\title{
Use of Geostatistics in Designing Sampling Strategies for Soil Survey
}

\author{
H. J. Di, B. B. Trangmar* and R. A. Kemp
}

\begin{abstract}
Semivariograms are used to quantitatively assess spatial variability of depth to mottles, depth to gravels, and thickness of loamy sand and/or coarser-textured layers, which are definitive criteria for classification of soils derived from alluvium on the Canterbury Plains near Lincoln College, New Zealand. The three properties vary anisotropically with the anisotropy ratio being highest for depth to mottles $(k=5.84)$, lowest for thickness of loamy sand and/or coarser-textured layers $(k=1.58)$, and intermediate for depth to gravels $(k=2.43)$. Directions of maximum variation for depth to mottles and depth to gravels are NE-SW across an abandoned channel hollow. This pattern is reflected in the soil map of the study area and in the smaller-scale soil map of the adjacent region. Such variation reflects the past regional drainage patterns of channels flowing predominantly in a NW-SE direction. The appropriate field configuration of a sampling scheme for future survey of similar adjacent soils would be rectangular with a sample spacing in the direction of least variation $k$ (anisotropy ratio) times that in the direction of maximum variation. Suitable sample numbers and sampling intervals to achieve desired levels of precision in the direction of maximum variation are determined. These are obtained from graphs showing relationships between kriging standard error, sample spacing and sample number. This geostatistical approach is more efficient than conventional statistical methods in designing sampling strategies: less samples are needed for kriging than for the conventional method to achieve the same level of precision.
\end{abstract}

Coll is a THREe-Dimensional body whose properties vary spatially as a result of interacting environmental factors. In same cases, there may be only one or two dominant factors that govern formation and distribution of soils in a specific region. Soils derived from alluvium are often highly variable (Karageorgis, 1980; Mausbach et al., 1980; Wilding and Drees, 1983) because of marked vertical and lateral changes of texture within the parent materials. Spatial variation of soil properties in alluvial systems has traditionally been qualitatively assessed and partitioned by field survey and mapping. Application of geostatistical techniques have recently allowed a more quantitative approach to be undertaken (Burgess and Webster, 1980a; Webster, 1985; Trangmar et al., 1985, 1986; Warrick et al., 1986).

Soil surveyors are often confronted with the dilemma of how many observations should be made and where they should be located in the field. This is particularly true in flat alluvial systems where the inherent spatial variability of soil properties is not easily predicted from soil-landform relationships.

The conventional statistical approach to soil variability assumes that variation of properties within sampling units is random or spatially uncorrelated. It

H.J. Di and R.A. Kemp, Dep. of Soil Science, Lincoln College, Canterbury, New Zealand; and B.B. Trangmar, N.Z. Soil Bureau, DSIR, Christchurch, New Zealand. Contribution of the Dep. of Soil Science, Lincoln College, New Zealand and N.Z. Soil Bureau, DSIR, Christchurch, New Zealand. Received 8 Sep. 1988. *Corresponding author.

Published in Soil Sci. Soc. Am. J. 53:1163-1167 (1989). also assumes that the sample mean is the best estimate of a soil property at any location within the sampling area, and that estimation precision is characterized by parameters such as variance, standard error and confidence limits. The number of samples needed for estimating the mean values of a soil property within a sampling unit can then be determined from the following formula (Cline, 1944)

$$
n=t \alpha^{2} s^{2} /(x-\mu)^{2}
$$

where $n$ is the number of observations needed for the estimation of mean $\mu$ with a tolerable deviation of $x$ $-\mu$, if the variance is $s^{2}$. The quantity $t \alpha$ is the student's $t$ at the chosen level of confidence.

Studies using geostatistics have shown that soil properties often tend to be spatially correlated (Burgess and Webster, 1980a; Trangmar et al., 1985, 1986; Webster, 1985; Warrick et al., 1986). The classical statistical model is suboptimal for determining sampling numbers under such conditions because it takes no account of spatial correlation and relative positions of sampling locations.

Geostatistics provides a tool for improving sampling design by utilizing the spatial dependence of soil properties within sampling regions. The kriging estimation variance for predicting soil property values at unsampled locations (Burgess and Webster, 1980a,b) depends on the degree of spatial dependence, which is expressed by the semivariogram, and on the configuration of observation points in relation to the area to be estimated. The minimized estimation variance $\left(\sigma_{\mathrm{k}}^{2}\right)$ for block kriging is obtained from the expression

$$
\sigma_{\mathrm{k}}^{2}=\sum_{i=1}^{n} \lambda_{\mathrm{i}} \bar{\gamma}\left(x_{i}, B\right)+\Psi_{B}-\bar{\gamma}(B, B)
$$

where $\bar{\gamma}\left(x_{\mathrm{i}}, B\right)$ is the average semivariance between observation points $x_{\mathrm{i}}$ in the neighborhood and points within the block $B, \bar{\gamma}(B, B)$ is the average semivariance between all points with the block (i.e., the withinblock variance) and $\Psi_{B}$ is the Lagrange parameter associated with minimization. McBratney and Webster (1983) applied the theory to regional soil sampling and suggested that the actual efficiency achieved in their studies was three to nine times greater than that estimated by the classical statistical methods. Unfortunately, few other studies of this kind have been made to substantiate this claim.

The aim of this study was to determine the utility of geostatistics in assisting design of a sampling scheme for soil morphological properties in an alluvial system. Depth to distinct mottles, depth to gravels, and thickness of loamy sand and/or coarser-textured layers are currently used as differentiae for classification of soils derived from alluvium near Lincoln College on the Canterbury Plains, New Zealand, at soil series or type levels (Cox, 1978). Spatial variability of these properties are assessed and interpreted in terms of the depositional history of the alluvial system. Anisotropic semivariogram parameters and kriging stan- 
dard errors are then used to suggest appropriate sampling strategies for future surveys of similar soils at the same scale on the adjacent area.

\section{MATERIALS AND METHODS}

\section{Physiography}

The study was conducted on a 10-ha area of the Lincoln College Research Farm, $20 \mathrm{~km}$ south of Christchurch on the Canterbury Plains, South Island, New Zealand (Fig. 1). The Canterbury Plains cover about $7500 \mathrm{~km}^{2}$ and consist of overlapping flat to gently undulating glacial outwash fans deposited during the Quaternary by eastward-flowing rivers draining the Southern Alps. The outwash fans are mainly comprised of gravels overlain towards the toe of the fans by thin silt loam to sandy-textured sediments. Parent rocks of the fan deposits are indurated sandstone and siltstone with some argillite.

The climate in the region is subhumid and cool temperate. The mean annual rainfall is relatively low compared with other parts of New Zealand, varying from $650 \mathrm{~mm}$ near the coast to about $1000 \mathrm{~mm}$ at the western edge of the Plains. Mean annual temperatures range from $10^{\circ} \mathrm{C}$ to $12{ }^{\circ} \mathrm{C}$. Soils on the Canterbury Plains are mainly Inceptisols and Entisols (Soil Survey Staff, 1975), used intensively for cropping, horticulture and some exotic forestry.

The 10-ha study area has been used for animal grazing experiments since 1981. A remnant channel extends across the eastern part of the area in a NW-SE direction (Fig. 2). The maximum elevation difference in the channel area is about $0.6 \mathrm{~m}$. The rest of the area slopes very gently $\left(0.3^{\circ}\right)$ from the top of the channel bank towards the SW.

\section{Soil Survey}

One hundred and six screw auger observations were made at intersections of a 30 by $30 \mathrm{~m}$ grid across the L-shaped study area (Fig. 2). The 30-m observation interval was based on results of previous work in the region (Karageorgis, 1980). Depth to distinct mottles, gravels, and thickness of

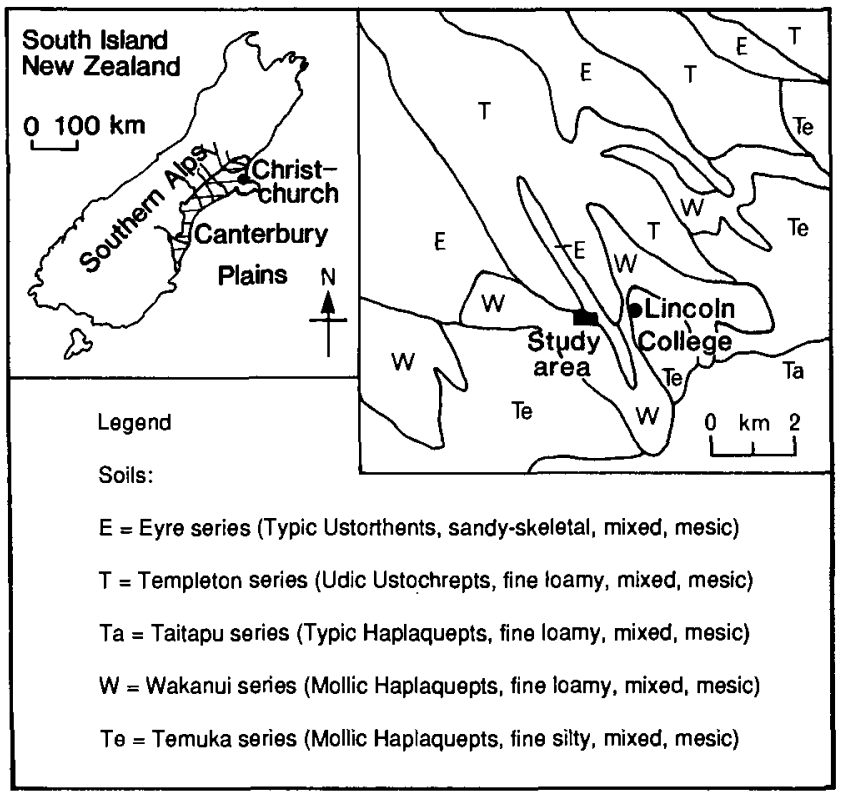

Fig. 1. Location map of the study area illustrating the shape and orientation of soil mapping units in the adjacent region (after Kear et al., 1967). loamy sand or sand were described (Taylor and Pohlen, 1979) to $1 \mathrm{~m}$ depth or shallower where gravels were encountered. Once encountered within auger holes, gravels were assumed to continue to depth on the basis of exposures in soil pits and in an adjacent quarry. The quarry faces indicated that the thin $(<2 \mathrm{~m})$ silt loam to fine sand surface layer was underlain by continuous outwash gravels to at least $7 \mathrm{~m}$ depth.

The properties measured are used to define soil series or types in the region (Cox, 1978). Soils in the study area have been separated into Eyre, Templeton, and Wakanui series (Di and Kemp, 1989). Eyre series, sandy-skeletal, mixed, mesic Typic Ustorthents) are defined where depth to gravels is less than $45 \mathrm{~cm}$. Templeton series (fine loamy, mixed, mesic Udic Ustochrepts) occur where depth to gravels exceeds $45 \mathrm{~cm}$ in levee deposits. They are well drained, and distinct subsoil mottles are absent. Wakanui series (fine loamy, mixed, mesic Mollic Haplaquepts) are imperfectly drained (Taylor and Pohlen, 1979) with distinct subsoil mottling.

\section{Geostatistical Analysis}

The spatial variability of the three properties was analyzed using geostatistics. Semivariograms were computed for each property in four different directions (i.e., NE-SW, E-W, SENW and N-S), each with a direction tolerance of \pm 22.5 degrees using the VAR2 program (Yost et al., 1986).

Differences in slopes for semivariograms computed in different directions indicated that the three morphological properties varied anisotropically. A linear geometric anisotropic model was fitted by a weighted least squares method to the pooled directional semivariances for each property. The anisotropic model used was (Trangmar et al., 1985)

$$
\begin{aligned}
& \gamma(\theta, h)= \\
& C_{0}+\left[A \operatorname{Cos}^{2}(\theta-\Psi)+B \operatorname{Sin}^{2}(\theta-\Psi)\right] h
\end{aligned}
$$

where $\gamma(\theta, h)$ is the semivariance in the direction $\theta$ at distance of separation $h, C_{0}$ is the nugget variance, $\Psi$ is the direction of greatest variation (i.e., the direction in which the semivariogram slope is steepest), $A$ is the slope of the semivariogram in the direction of maximum variation, and $B$ is the slope of the semivariogram in the direction perpendicular to that of the maximum variation. The anisotropy ratio, $k$, was determined as

$$
k=A / B
$$

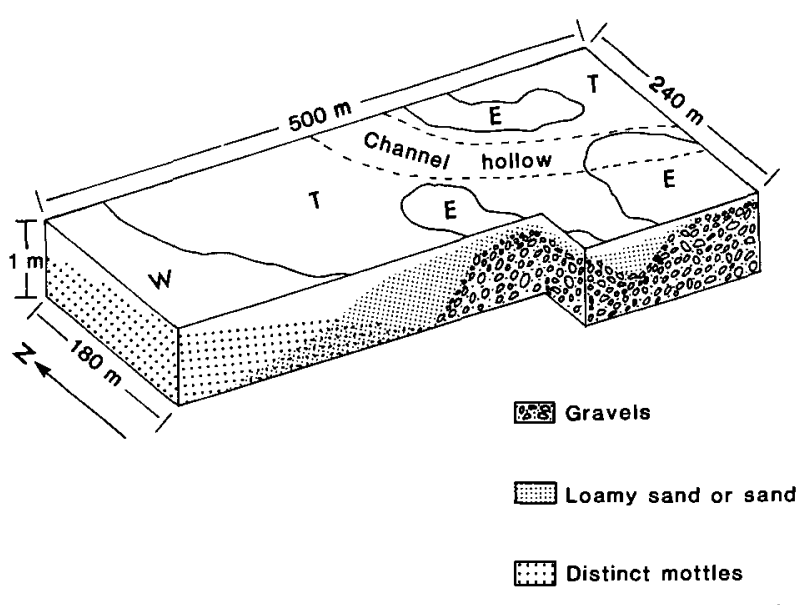

Fig. 2. Schematic illustration of variation of the three morphological properties in the study area. E: Eyre series; T: Templeton series; W: Wakanui series. 
Table 1. Parameters of linear anisotropic models fitted to semivariances of depth to mottles, depth to gravels, and thickness of sandy layers.

\begin{tabular}{|c|c|c|c|c|c|c|c|c|c|}
\hline Soil properties & $\bar{x}+$ & $s^{2}$ & $C_{0}$ & $A$ & $B$ & $\begin{array}{c}k \\
(A / B)\end{array}$ & $\Psi$ & $r^{2}$ & $\mathrm{DF}$ \\
\hline & $\mathrm{cm}$ & & & & & & & & \\
\hline $\begin{array}{l}\text { Depth to mottles } \\
\text { Depth to gravels } \\
\text { Thickness of sand layers }\end{array}$ & $\begin{array}{l}74 \\
82 \\
41\end{array}$ & $\begin{array}{r}1219 \\
771 \\
689\end{array}$ & $\begin{array}{l}222 \\
181 \\
392\end{array}$ & $\begin{array}{l}9.76 \\
3.74 \\
1.94\end{array}$ & $\begin{array}{l}1.67 \\
1.54 \\
1.23\end{array}$ & $\begin{array}{l}5.84 \\
2.43 \\
1.58\end{array}$ & $\begin{array}{r}51^{\circ} \\
43^{\circ} \\
7^{\circ}\end{array}$ & $\begin{array}{l}0.95 \\
0.86 \\
0.69\end{array}$ & $\begin{array}{l}60 \\
67 \\
68\end{array}$ \\
\hline
\end{tabular}

$+\overline{\mathrm{x}}$ : mean.

$s^{2}$ : general variance.

$C_{0}$ : nugget variance.

$A$ : slope of the semivariograms in the direction of maximum variation.

$B$ : slope of the semivariograms in the direction perpendicular to that of the maximum variation.

$k$ : anistropy ratio.

$\Psi$ : direction of maximum variation (degrees $\mathbf{E}$ of $\mathbf{N}$ ).

$r^{2}$ : proportion of variance explained by the linear geometric anistropic model.

DF: degrees of freedom.

The derived anisotropic semivariogram parameters for each property were then used to determine appropriate sampling strategy for future soil survey and variability studies in similar soils of the adjacent area. Block kriging estimation errors, Eq. [2], for each property were computed for cells of different sizes and for different sampling intervals in the direction of maximum variation with the interpolation points being centered at the middle of grid cells. Kriging standard errors (kriging SE) for each property were calculated for a range of observation numbers using the OSSFIM program of McBratney and Webster (1981). Conventional standard errors (conventional SE) of the mean were calculated for a range of sample numbers and compared with those derived from block kriging.

\section{RESULTS AND DISCUSSION}

\section{Soil Pattern}

Soil parent materials in the study area and neighboring region were deposited by migrating braided rivers and/or distributive channels. Soil morphological features within the upper $1 \mathrm{~m}$ soil profile are partly related to the final depositional phases. The spatial distribution of mottles, gravels and sandy layers in the study area is schematically illustrated in Fig. 2.

A channel hollow extends from NW to SE through the study area. Gravels occur at shallow depths on the eastern part adjacent to the channel hollow. Depth to

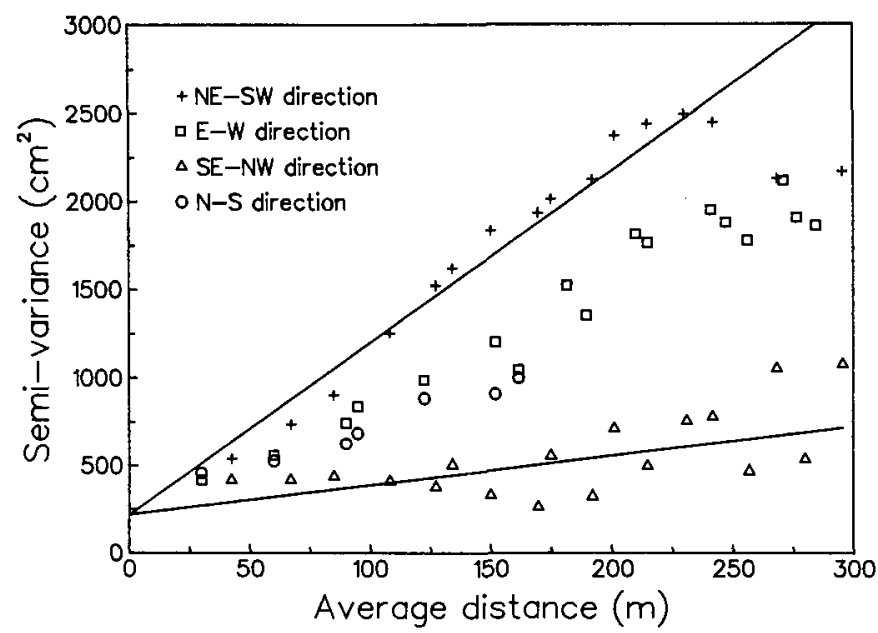

Fig. 3. Linear geometric anisotropic model for depth to mottles. The two solid lines define the envelope within which the fitted model lies. gravels increases away from the channel hollow to the southwest part of the region where thickness of overlying fine-textured sediments exceeds $1 \mathrm{~m}$ (Fig. 2). This distribution pattern suggests that these gravels may be channel bar deposits left by braided rivers that migrated across the region. There are thick layers of loamy sand and sand on the central and eastern parts of the area. These layers thin towards the southwest and are gradually replaced by silt loam and clay loam textured material, although occasional sandy bands still occur in places. These spatial patterns of texture and depth to gravels suggest that the gravels have been buried by levee deposits adjacent to the channel hollow. The levee deposits thin toward the southwest and grade into floodbasin deposits (Fig. 2).

The spatial distribution of subsoil mottles is closely related to depth to gravels and thickness of sandy layers. Distinct mottles occur throughout the profiles of the Wakanui soils in the southwest part of the area where sandy layers are thin and subsoil textures vary from silt loam to clay loam. Depth to mottles increases towards the east as subsoil permeability increases due to thicker layers of loamy sand or sand, and soils change from Wakanui to Templeton series. Profiles of the Eyre soils in the eastern part of the area, where gravels have not been deeply buried by finetextured materials, are well drained and subsoil mottling is absent (Fig. 2).

\section{Anisotropic Spatial Dependence}

Semivariograms of each property differ considerably in slope with direction. Anisotropic models were fitted to the linear parts of directional semivariograms to quantify the anisotropic variability of each property. Parameters estimated from these anisotropic models are summarized in Table 1, and the fitted linear geometric anisotropic model for depth to mottles is shown in Fig. 3.

The differences in nugget variance $\left(C_{0}\right)$ of the three properties suggest that thickness of loamy sand (or coarser) has a much larger short-range variation than either depth to mottles or depth to gravels. A considerable amount of the variation in sandy layers is thus present in distances shorter than the sampling interval of $30 \mathrm{~m}$. This is consistent with the rapid vertical and lateral changes in texture associated with such a highly variable depositional environment.

The anisotropy ratios $(k)$ are all greater than unity, 
indicating that the three soil properties are more variable in certain directions than others. The anisotropy of all properties reflects small down stream variation of the alluvial deposits and subsequent soil drainage, yet marked lateral variation normal to the channel hollow.

Strong anisotropy of depth to mottles $(k=5.84)$ results from deteriorating soil drainage conditions in a NE-SW direction $\left(\Psi=51^{\circ} \mathrm{E}\right.$ of $\left.N\right)$ away from the channel hollow. Depth to gravels also varies most rapidly $(k=2.43)$ in the NE-SW direction $\left(\Psi=43^{\circ} \mathrm{E}\right.$ of $N$ ) as thickness of the overlying fine-textured materials increases away from the channel hollow. The NW-SE direction of minimum variation of both properties coincides with that of the channel hollow main axis.

The direction of maximum variation for thickness of loamy sand $\left(\Psi=7^{\circ} \mathrm{E}\right.$ of $\left.\mathrm{N}\right)$ also lies in the same quadrant as the other two properties. A smaller anisotropy ratio $(k=1.58)$, however, indicates a less marked directional influence, probably reflecting the spatial and temporal complexity of individual depositional flood events.

Close relationship of directions of maximum and minimum variation with depositional axes suggests that soil mapping units are likely to be elongated in the NW-SE direction (parallel to the channel hollow) with a short axis in the NE-SW direction. Such a pattern is indicated in the detailed soil map of the study area (Fig. 2), and also strongly reflected in the smallerscale soil map of the adjacent larger region (Kear et al., 1967) (Fig. 1). This regional soil pattern reflects the major depositional axes of former migrating channels of the NW-SE flowing rivers which drain the Canterbury Plains.

\section{Sampling Strategies for Soil Survey}

An optimal sampling scheme in any study should be one that provides the maximum estimation precision with the least sampling effort. As far as soil mapping is concerned, it is desirable for a survey to involve the minimum number of observations necessary to estimate the mean values (at acceptable precision levels) of soil properties within areas of specified sizes (e.g., the smallest unit delineated on the soil maps at certain scales). The sampling interval of 30 $\mathrm{m}$ used in this study was derived from a qualitative soil-landscape model developed by Karageorgis (1980) for morphological properties of similar soils in an adjacent field. The anisotropic semivariograms and block kriging were used to augment this model by identifying statistically optimal sample spacings for a range of sample sizes and desired levels of local estimation precision.

The relationships between kriging standard error and sample spacing for 100 by $100 \mathrm{~m}$ blocks were calculated for each property in directions of maximum variation for a range of sample sizes. The block size was chosen arbitrarily to represent the smallest unit likely to be delineated on a soil map of the study area. Results shown for depth to mottles in Fig. 4 are similar to those for the other two properties.

The kriging SE generally decreases inversely with sample numbers (Fig. 4), although it tends to have the

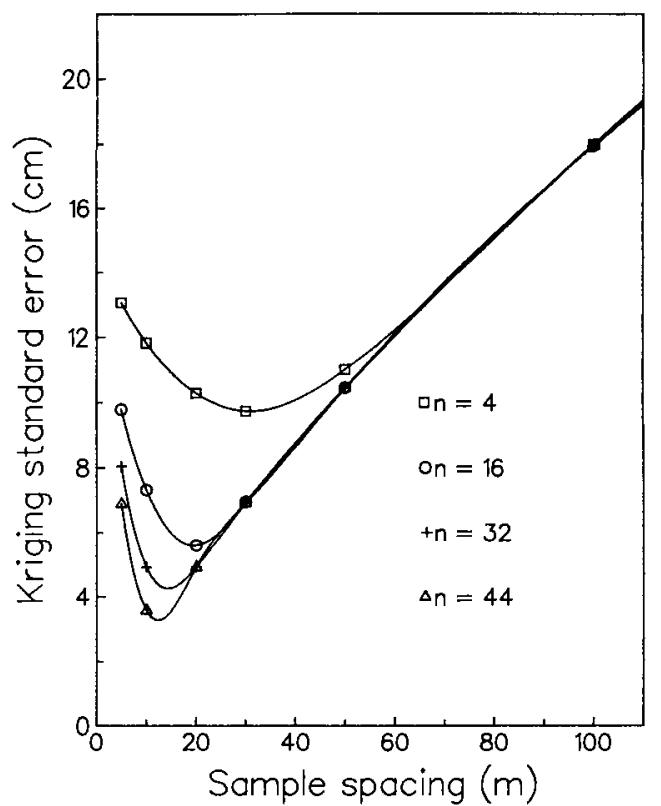

Fig. 4. Relationships between kriging standard error and sample spacing in the direction of maximum variation for different numbers of observations $(n)$ within a 100 by $100 \mathrm{~m}$ block for depth to mottles.

same value irrespective of sample number beyond a certain sample spacing. The kriging SE for a given sample size initially decreases, then increases rapidly, with increase in sample spacing. These relationships are a function of the spatial configuration of samples in relation to the size of the block under study. The kriging SE is large when the sample spacing is very small, because sample points are clustered near the center of the block. The sample points become more widely spread within the block as sample spacing increases, and the kriging SE therefore decreases. The SE is minimized when sample spacing increases such that observations are evenly spread throughout the kriged region. Any further increase in sample spacing gives rise to an increase in kriging SE as the observations are separated too far apart, and some are located outside the estimated areas.

A statistically optimal sampling scheme, based on the appropriate sample spacing in the direction of maximum variation and the number of observations required, can be determined if a tolerable error with a certain confidence level is specified for any of the three soil properties. For example, if an estimate of depth to mottles within every 100 by $100 \mathrm{~m}$ block is required, and a maximum tolerable standard error of $5.5 \mathrm{~cm}$ is acceptable for each estimate, the optimal sample size read from Fig. 4 would be 16. The optimal sample spacing in the direction of maximum variation would be $20 \mathrm{~m}$ and about $120 \mathrm{~m}$ in the direction of minimum variation. The latter spacing results because variation of depth to mottles in the region is anisotropic with a ratio $=5.84$ (Table 1 ). The resulting sampling scheme should be in the form of a rectangular grid elongated in the direction of least variation.

If only a limited number of observations can be afforded, the graphs can also be used to indicate the appropriate sample spacing in accordance with the 


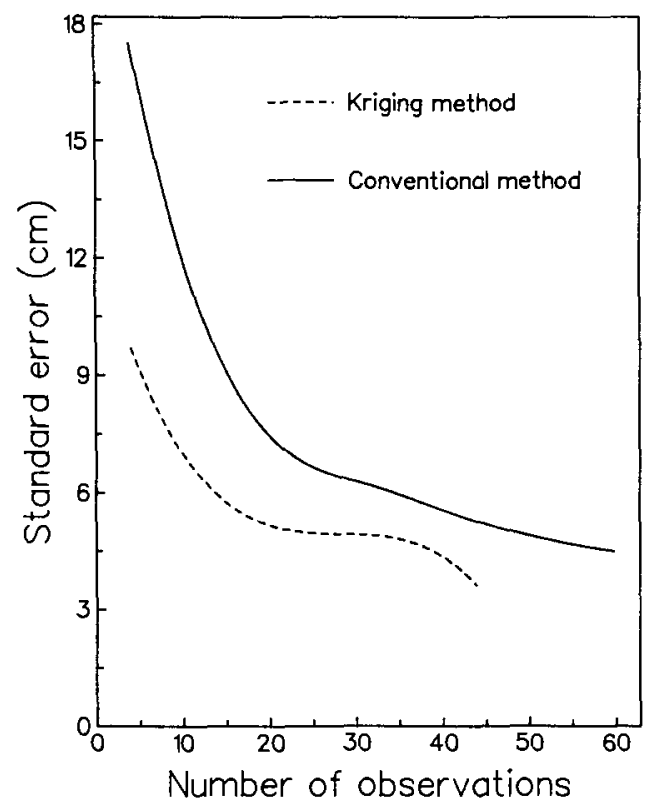

Fig. 5. Kriging and conventional statistical standard error in relation to sample size for estimating depth to mottles over 100 by 100 m blocks.

minimum kriging SE. For example, the optimal sample spacing (Fig. 4) in the direction of maximum variation should be about $30 \mathrm{~m}$ to minimize kriging $\mathrm{SE}$ if only 4 observations can be afforded to estimate depth to mottles of every 100 by $100 \mathrm{~m}$ area in the region.

The minimized SE for each of the three soil properties derived from kriging and the conventional statistical approach were plotted against the number of observations for 100 by $100 \mathrm{~m}$ (1 ha) blocks. Figure 5 shows an example for depth to mottles. The other two properties displayed similar patterns.

The kriging SE is considerably lower than that estimated by the conventional method for the same number of observations (Fig. 5). Kriging therefore requires less observations than the conventional statistical method to achieve the same precision. For example, if depth to mottles is to be estimated for a 1 ha block, and the maximum tolerable error is $6 \mathrm{~cm}$, only 14 samples are required for kriging, but 34 are needed for the conventional statistical method. These results are similar to those obtained by McBratney and Webster (1983), who claimed a three- to nine-fold gain in efficiency by kriging over the conventional statistical method. This gain is explained by the fact that kriging takes into account the spatial dependence between observations in the region, whereas random variation is assumed by conventional statistical theory.

Quantitative analysis of soil spatial variability can augment genetic concepts of soil formation and distribution to develop more robust soil-landscape models. The study shows that semivariogram analysis of directional differences in variation can help quantify and improve understanding of anisotropic spatial effects of soil-forming processes. Such analysis can, in turn, be used to improve local estimation precision by using anisotropic semivariogram models in kriging
(Trangmar et al., 1986). It can also help define optimal sampling size and field sample configuration for different levels of estimation precision in areas where the semivariogram is known or is transferable.

In the case of known anisotropy reconnaissance sampling to establish the semivariogram should be made at variable spacing along transects oriented in the perceived direction of maximum variation. The conventional statistical approach should be used to determine sample numbers if no spatial dependence is detected in the reconnaissance survey. In the situation where properties vary at different rates, the sampling strategies should be determined according to the parameter most relevant to the study objective, or based on the most variable property if the properties are equally important.

\section{ACKNOWLEDGMENTS}

The authors are grateful to the Education Commission of China for their financial support of part of this project, and to Dr. P. Tonkin, Dr. R. McLaren, Dr. G. Buchan, H.J. Siefkes-Boer and L. Samuelu for their advice or technical assistance.

\section{REFERENCES}

Burgess, T.M., and R. Webster. 1980a. Optimal interpolation and isarithmic mapping of soil properties. I: The semivariogram and punctual kriging. J. Soil Sci. 31:315-331.

Burgess, T.M., and R. Webster. 1980b. Optimal interpolation and isarithmic mapping of soil properties. II: Block kriging. J. Soil Sci. 31:333-341.

Cline, M.G. 1944. Principles of soil sampling. Soil Sci. 58:275-288.

Cox, J.E. 1978. Soils and agriculture of part of Paparua County, Canterbury, New Zealand. N.Z. Soil Bur. Bull. 34.

Di, H.J., and R.A. Kemp. 1989. Variation in soil physical properties between and within morphologically-defined taxonomic units. Aust. J. Soil Res. 24(2) (in press).

Karageorgis, D. 1980 . Soil variability and related crop productivity within a sample area of the Templeton soil mapping unit. M. Ap. S. thesis, Lincoln College, Canterbury, New Zealand.

Kear, B.S., H.S. Gibbs, and R.B. Miller. 1967. Soils of the Downs and Plains, Canterbury and North Otago, New Zealand. N.Z. Soil Bur. Bull. 14.

Mausbach, M.J., B.R. Brasher, R.D. Yeck, and W.D. Nettleton. 1980. Variability of measured properties in morphologically matched pedons. Soil Sci. Soc. Am. J. 44:358-363.

McBratney, A.B., and R. Webster. 1981. The design of optimal sampling schemes for local estimation and mapping of regionalized variables. II: Program and examples. Comput. Geosci. 7:335-365.

McBratney, A.B., and R. Webster. 1983. How many observations are needed for regional estimation of soil properties? Soil Sci. 135:177-183.

Soil Survey Staff, 1975. Soil taxonomy: A basic system of soil classification for making and interpreting soil surveys. USDA-SCS Agric. Handb. 436. U.S. Gov. Print. Office, Washington, DC.

Taylor, N.H., and I.J. Pohlen. 1979. Soil survey method. N.Z. Soil Bur. Bull. 25.

Trangmar, B.B., R.S. Yost, and G. Uehara. 1985. Application of geostatistics to spatial studies of soil properties. Adv. Agron. 38:45-94.

Trangmar, B.B., R.S. Yost, and G. Uehara. 1986. Spatial dependence and interpolation of soil properties in West Sumatra, Indonesia: I. Anisotropic variation. Soil Sci. Soc. Am. J. 50:13911395.

Warrick, A.W., D.E. Myers, and D.R. Nielsen. 1986. Geostatistical methods applied to soil science. In A. Klute (ed.) Methods of soil analysis. Part 1: Physical and mineraological methods. 2nd ed. Agronomy 9:53-81.

Webster, R. 1985. Quantitative spatial analysis of soil in the field. Adv. Soil Sci. 3:1-70.

Wilding, L.P., and L.R. Drees. 1983. Spatial variability and pedology. p. 83-116. In L.P. Wilding et al. (ed.) Pedogenesis and soil taxonomy. I: Concepts and interpretation. Elsevier, Amsterdam.

Yost, R.S., B.B. Trangmar, and J.P. Ndiaye. 1986. Geostatistical computation software for microcomputers. I: Semivariograms. Hawaii Inst. Trop. Agric. Hum. Resour. Res. Ext. Ser. 74, Univ. of Hawaii, Honolulu, HI. 